\title{
AN ASSESSMENT OF SCHOLARLY CONTRIBUTIONS AND WEB VISIBILITY AMONG SCIENTISTS OF CSIR-BUILDING AND ROAD RESEARCH INSTITUTE, GHANA
}

\author{
N. A. Mingle*, N. K. Achampong And D. L. Acheampong \\ (N. A. M.: CSIR - Institute of Scientific and Technological Information (INSTI); \\ N. K. A.: CSIR - Building and Road Research Institute (BRRI); D. L. A.: \\ CSIR - Crops Research Institute (CRI)). \\ *Corresponding author's email: nakmingle@gmail.com
}

\begin{abstract}
The introduction of the internet has revolutionized the dissemination and assessment of research outputs with renewed emphasis on the impact of scholarly publications. The purpose of this study was to measure scholarly presence and citation impact of research scientists of the Building and Road Research Institute (CSIR-BRRI) on the internet. Bibliometrics was employed as a quantitative research method for this study. using Google Scholar. The results showed that majority $(77.5 \%)$ of scientists had at least one scholarly reference on the internet. It also found that, almost all (96.5\%) scientists who had scholarly works online showed affiliation to the CSIR-BRRI. Again, it was observed that most mentions/hits were journal publications (59\%) followed by thesis (35\%). However, the study found that there was a weak positive relationship between number of journal articles and citations online, a clear indication that a web presence does not automatically reflect the usefulness of a scholarly output. It is recommended that scientists identify and research into globally relevant topics and also publish in reputable journals to enhance their visibility.
\end{abstract}

Keywords: Scholarly publishing, web visibility, citations, Google Scholar, scientific publications, scientists.

\section{Introduction}

Measures and scales of assessment have been used in all spheres of life and academia is no exception. In academia, publishing is one of the major determinants of "who is who." It is the measure of a person's scholarly output and is often used as a standard for promotion, hiring and tenure (Moher et al., 2016). Universities and research institutions have assessed the performance of academic/faculty and research staff based on the scholarly output of their employees. Research publications form an integral part of operations of research institutes, government agencies and academic departments of universities particularly in the sciences. Indeed, scientific publications play a central role in systematically documenting research findings and facilitating the exchange of information between researchers (Mensah \& Bekoe, 2010; Klain- Gabbay \& Shoham, 2018). Reputation in scholarly publishing is considered a measure of how a scholar/ scientist is regarded among peers or colleagues in the same subject area (Hermann, 2018). It is often determined by the number of research publications and novel contributions to a scientists' area of research. Among scientists and the scholarly community, publishing is 
the measure of a scientists' impact in the area of specialisation. In fact, scholarly publishing is the basis for promotion in the Council of Scientific and Industrial Research, (CSIR) Ghana, as stated in Section 38 of the CSIR Revised Conditions of Service for Senior Members (2008), that "promotions shall be made according to merit, and in determining this, account shall be taken of publications."

Theinternetproves to bean excellenttool for showcasing scholarly prowess. It serves as a platform to showcase academic presence and prominence; the phenomenon of being present on the internet is known as web visibility. Visibility according to Hermann (2018), has become the new name of the scholarly reputational game and refers to allowing one's work in the scholarly market place. Chung \& Park (2012), examined web visibility of researchers in the field of communication and defined web presence as the number of web (co) mentions of a researcher. Some studies report that dissemination of scientific publications via the web was becoming very popular and there were discussions of the possibility of a web mention being comparable to a research citation for evaluating the impact of academic activity (Costas et al., 2015, Haustein et al., 2014). Evaluating researchers and their research impact in modern times have become increasingly popular since a researcher's number of publications can easily be retrieved from any major research database such as Pubmed, Scopus, Web of Science, Google Scholar, or Research Gate (Agarwal et al., 2016.)

Several studies have used Google and Google Scholar to assess web visibility (Orduna-Malea \& Lopez-Cozar, 2015; Dorsch 2017). Introduced in November 2004, Google scholar is a web search engine freely accessible via the internet and focuses on indexing the full text or metadata of scholarly publications across an array of publishing formats and disciplines (Aboushok, 2015); it is estimated to hold approximately 80 to $90 \%$ of all articles published in English with indications that it has significantly expanded its coverage over the years (Halevi et al., 2017). This index includes most peer reviewed online academic journals and books, thesis and dissertations, preprints, abstracts, technical reports, and other scholarly literature including patents and offers free universal access (Lopez-Cozar et al., 2014; Shultz, 2007). Lim \& Park (2011), studied how congressional members appeared on the web by tracking the web visibility of South Korean Politicians and operationally defined web visibility as the number of webs mentions of each congressional member. To be visible, information must be reasonably complete and found with relative ease (Michener \& Bersch, 2013). Regarding academic publications, web presence indicators may include: keywords (pointers to a scientists' area of specialization, choice of journal (journal impact factor), parent institution (website mentions/profiles and Institutional Repository), number of hits (total number of works/articles in a Google search; and citation counts (how many times an individual have been cited).

A hit can simply be described as a web appearance or mention. Hits and views are important when measuring the availability, appearances and presence of published works on the internet; but do not determine use and impact of scholarly productivity. It may be useful in measuring visibility, however, on their own, do not represent an accurate measure of scholarly impact (Barnes, 2015; Agarwal, 2016). Other advanced bibliometric methods such as Citation analysis have emerged over time to augment the use of hits/publication counts by assessing how a 
published work has been cited (used) by other scholars in a given field. Ding et al. (2016), have stated that the analysis of scholarly communication through citation patterns has been extensively used to detect scientific collaboration, map the landscape of scholarly disciplines, assess the impact of research outputs, and observe knowledge transfer across domains. Thus, citation analysis serves as a powerful quantitative method for quantifying researchers' scientific impact in order to evaluate and compare scholars in hiring, funding and tenure decisions (Agarwal, 2016). In academia, articles that receive more attention from other scholars in terms of citations are generally considered more important and prestigious. Although scientists may alternatively refer to scholars" "scientific reputation" (opinions generally held by peers about a scholar), the multi-dimensional nature of this notion generates a mix of explicit (e.g., bibliometric indicators) and nebulous measures e.g., certain valued qualities such as fair play, integrity, honesty, caring, etc. (Parra, 2011). However, measurement of author productivity/impact seems to depend largely on number of citations, and citations are typically related to the paper's visibility (Ale Ebrahim, 2014). Some scholars have also expressed scholarly impact as the author/s' most cited publication (Abramo, 2018; Aguinis et al., 2012). Thus, counting of publications is a major criterion for assessing a researcher's output (Kulczycki, 2017).

Presently, the interest in web presence/ appearance and mentions coupled with the advantage of citation counts and journal impact factor is generating new areas of relational analysis between publication related factors. Some studies have found a weak but statistically significant relationship between web mentions and citations on Social Science
Index (Costas et al., 2014; Chung \& Park, 2012). This is indicative that a web mention (visibility) does not necessarily suggest use (citation counts) of the article. In other words, visibility is having a presence on the internet, so that other information seekers can locate authors and their publications

The Building and Road Research Institute (BRRI) is one of the thirteen Institutes of the Council for Scientific and Industrial Research (CSIR) in Ghana. It was established in 1952 as the West African Building and Road Research Institute and has evolved over the years. Since its inception, scientists at the Building and Road Research Institute have published severally in all forms of media to communicate research findings and to rise through the promotion ladder. "Currently, scientific research in CSIRBRRI is grouped under the following areas: Structures, Design and Planning; Materials Engineering; Geotechnical Investigations; Transportation Engineering; Land Surveying and Mapping/Geospatial and Construction. In the past, there were indications in the CSIRBRRI Annual Reports that there was research focused on Granite, earthquakes, bamboo as a building material, paint, flooding control; earth buildings and several others. Most of the previous research papers are in print and are available in the Institute's library, but no present research has attempted to explore whether some of these brilliant scientific works are available on the internet. Again, there is no present study assessing research publications of BRRI scientists and their present specializations within the various areas of research. Also, following a recent directive from management of the CSIR that scientists must publish in reputable journals to further uplift the image of the CSIR as a whole, an assessment of scientists' visibility could 
provide a general outlook of the publishing trend among scientists on the internet. Again, since marks for promotion are awarded based on the quality of the research work and the reputation of journals or conferences for the communication of the research, scientists have no choice than to consciously enhance their scholarly reputation both locally and internationally hence the need to study web visibility trends and make appropriate recommendations.

\section{Purpose of the study}

The purpose of this study was to assess the scholarly presence of CSIR-BRRI Scientists on the internet through publication counts and measure impact through citation counts. Specifically, this study was guided by the following research questions: 1 . To what extent were scientists of the CSIR-BRRI and their publications visible on the internet? 2. Are there differences in scholarly visibility based on gender? 3. Which forms of publishing were BRRI Scientists using most predominantly? 4. Which fields of study/themes were BRRI scientists publishing in and 5? What impact were they making as people view and cite their research works?

\section{Theoretical framework}

The study of web visibility is relatively new and there are still evolving trends with regard to research in the area. One of the theories that is relevant in any information science research is the Information Lifecycle Theory. The theory originated in the USA in 1934. Originally, the Information Life Cycle theory proposed that research information is created with the generation of an idea that is captured or stored in a medium; and disseminated for others to re-use to generate more ideas. Several studies have used the Information Lifecycle
Model to study management and preservation of information (Cox \& Tam 2018; Carlson, 2014; Higgins, 2008).

There are five main constructs of the Information Life Cycle namely creation, distribution, use, maintenance and disposition (Sharma, 2011). Creation deals with the origination of a new idea by an individual or group of people in an organisation and in research organisations may include: these may include journal articles, conference papers, technical/research reports etc. The second phase is distribution which involves both internal (submission to the library, captured in reports etc) and external distribution or public distribution (captured in Annual Reports, databases, websites and other online provisions). The third construct is use of the information which includes the use of the information to generate further knowledge or improve some service or action. Maintenance is the fourth construct and involves the deliberate filing, retrieval and transfer of documents from active to passive thus ensuring an organised collection for an organisation. Disposition is the fifth major construct of the theory and deals with moving less used information to inactive collections (stack rooms) or completely discarding non useful materials. For the purpose of this study, the adopted version of the Information Life Cycle theory focuses on creation/collection, storage, dissemination and publication and re-use but not disposition since the online databases/ publishing houses are not owned by the CSIR and the researchers cannot assess disposition policies and practices. The emphasis of this study is on the scientists' efforts and choices with regard to creation (subject wise and type of publication), storage and dissemination (mode of availing the publication/ where to publish/publication counts), re-use (citation 
counts), and long-term access (ownership perspective in terms of where the document can be accessed from).

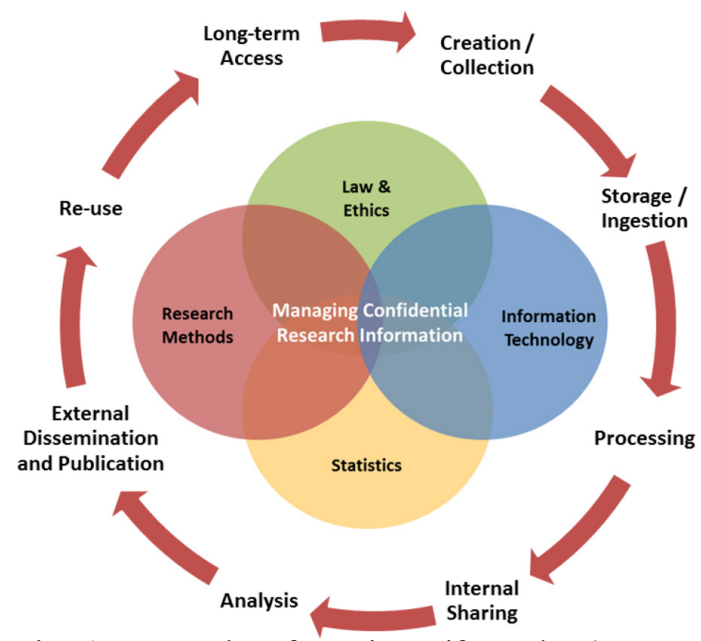

Fig. 1: Research Information Life cycle. (Source: Wood et al., 2014).

\section{Experimental}

This study adopted a quantitative research design, and used secondary sources on the internet to collect data for the study. The authors first requested a list of research scientists from the Administration/Human resources department of the CSIR-BRRI which constituted the population of the study. The total number of research scientists was 46 , since the population of research scientists was low, census sampling technique was employed for the study.

Using a computer connected to the internet, a query was made in the search box of Google Scholar for each scientist by entering his/her full name individually. All appearances were observed vigilantly to identify all hits which appeared on the first page of each search. Each hit was counted on a Spreadsheet by making a tally mark against the scientists' name under the appropriate categories (i.e., Journal article, conference papers, theses, etc.). Each scientist's name was entered and searched three times in order to check for consistency of the outcomes. Means, frequencies and percentages were calculated using the data gathered.

Using bibliometrics as a method to assess the level of visibility of CSIRBRRI Scientists, research question 1. To what extent were scientists of the CSIRBRRI and their publications visible on the internet was addressed by counting all hits that were found under all BRRI Scientists. In addressing research question 2. Are there differences in scholarly visibility based on gender, all hits made by males were grouped together and those made by females were also grouped together. In addressing research question 3. Which forms of publishing were BRRI Scientists using most predominantly, individual hit links were opened to ascertain what type of publication each hit was and then these were grouped under journal articles, thesis, etc. 4. Which fields of study/themes were BRRI scientists publishing in and in addressing research question 4 , which fields of study/themes were BRRI scientists publishing in? Each hit was assessed for a keyword which was captured into a notebook. Afterwards the Universal Decimal Classification (UDC) Scheme was used to develop subject themes that grouped some of the keywords into subject areas such as architecture, materials science, soil mechanics planning and survey etc. UDC is the scheme used to classify all publications in the Institute's library. Identified subject areas were later grouped under the five core divisions of the Institute to allow for comparative assessment. Ultimately, research question 5. What impact were CSIR-BRRI scientists making on the internet as people view and cite their research works was determined 
by counting citations made by every single hit and grouping all citations under focal areas of scientific research (most published subject areas) and the most cited research area and divisions respectively?

\section{Results and discussion}

In assessing the web visibility of scientists at the CSIR-BRRI, four main research questions were studied: Are scientists of the CSIRBRRI visible online as authors of scientific publications? Which forms of publishing are the scientists of the CSIR-BRRI using? And, what impact are the CSIR-BRRI scientists making in their fields of study (citations to ensure continuity of research)? On the average, ten (10) separate publications often appeared on the first search page and this formed the basis for assessment of the scientist. Out of this number, publications with the exact name of the scientists appeared first followed by other similar results. The following types of publications were of particular interest to the research scientists: conferences /seminars, journal articles, thesis, Institutional Repository appearances and Institutional affiliation.

TABLE 1

Gender distribution of scientists.

\begin{tabular}{clcc}
\cline { 2 - 4 } 1. & Gender & $\begin{array}{c}\text { Number of } \\
\text { Scientists }\end{array}$ & Percent (\%) \\
\cline { 2 - 4 } 2. & Male & 41 & 89.1 \\
\hline & Female & 5 & 10.9 \\
\hline
\end{tabular}

(Source: Field work (2018)

Over the years, the observation of gender inequality in education and particularly science related fields including Engineering and Mathematics have led to global concerns (Charlesworth \& Banaji, 2019). This study observed that there was a huge gender disparity among scientists of the CSIRBuilding and Road Research Institute. Only $11 \%$ of research scientists were females in contrast to the $89 \%$ male population. Thus, the scientist population of BRRI can be said to be a highly male dominated one. Out of the five female scientists, $2(40 \%)$ held $\mathrm{PhD}$ Degrees while the remaining held MPhil Degrees in their respective areas. Research work of female scientists were found in urban housing and planning, termite studies, architecture and pozzolana research. In Ghana, women scientists are less than $30 \%$ of the total scientists' population, while worldwide figures of women students and graduates in higher education have grown steadily in the last decade, women are still a minority in STEM fields, both in numbers of graduates (especially at $\mathrm{Ph} . \mathrm{D}$. level), and in the research professions (UNESCO, 2018). This observation is similar in studies relating to gender and career development where several research works have shown a gender difference, at least implicitly in professional settings (Carnes et al., 2015; Tomaskovic-Devey et al., 2006, FitzGerald et al., 2019). It also confirms an observation by UNESCO (2018), that, overall, women account for a minority of the world's researchers although some studies have reported an increase in the proportion of female authors (Gay-Antaki \& Liverman, 2018). In Ghana, women scientists are less than $30 \%$ of the total scientists' population, while worldwide figures of women students and graduates in higher education have grown steadily in the last decade, women are still a minority in STEM fields, both in numbers of graduates (especially at Ph.D. level), and in the research professions (UNESCO, 2018). 
Publication distribution (Hits) on Google Scholar

Again, in assessing the visibility of CSIRBRRI scientists, the various types of scholarly publications were examined and four distinct categories of hits were identified namely: Conferences, Journals, Thesis/Institutional Repositories and Scientists Profiles. Journals constituted the most (59\%), followed by Thesis $(35 \%)$ which were mainly found on Institutional Repositories, Conferences (4\%) and Profiles of Scientists on scholarly groups (2\%). Table 2 below gives a summary of Hits found in Google Scholar.

TABLE 2

Summary distribution of hits in Google Scholar based on the type of publication.

\begin{tabular}{|c|c|c|}
\hline $\begin{array}{l}\text { Publication } \\
\text { Type }\end{array}$ & $\begin{array}{l}\text { Number of } \\
\text { Hits }\end{array}$ & $\%$ \\
\hline $\begin{array}{l}\text { Conferences/ } \\
\text { Workshop }\end{array}$ & 8 & 4 \\
\hline $\begin{array}{l}\text { Journal } \\
\text { Thesis/ }\end{array}$ & 107 & 59 \\
\hline $\begin{array}{l}\text { Institutional } \\
\text { Repository }\end{array}$ & 63 & 35 \\
\hline Online Profiles & 3 & 2 \\
\hline TOTAL & 181 & 100 \\
\hline
\end{tabular}

(Source: Field work, (2018)).

This finding confirms the observations by (Kurtz \& Bollen, 2010) that citation data is mainly centered on journal articles focused on one scholarly activity and largely overlooking the activities of those not associated with the present publishing (and citation) system. The high number of hits in the journal article category as against conference hits may be due to the fact that most conferences still prefer to publish hard covers of Book of Abstracts and proceedings instead of archiving them on the Internet. Some of the hits are repetitive due to the fact that four or more scientists can publish one paper. Most scientists could not be found under the group conferences/workshop with only $4 \%$ visibility out of all hits made. This may be due to the fact that most conferences attended by scientists were not published or archived online as at the time of this study. Again, since scientists often publish journal articles out of conference presentations, there is the possibility that the conference papers were published as journal articles instead. Furthermore, the study ascertained whether the parent (CSIR-BRRI) featured in the web visibility of scientists and it was observed that all scholarly publications of CSIR-BRRI had references to the CSIR-BRRI as an Institute. Also, there was no indication of a book published by any scientist.

TABLE 3

Distribution of hits by CSIR-BRRI scientists using Google Scholar.

\begin{tabular}{llcc} 
& $\begin{array}{l}\text { Total Num- } \\
\text { ber of Hits }\end{array}$ & $\begin{array}{c}\text { Number of } \\
\text { Scientists }\end{array}$ & $\%$ \\
\cline { 2 - 4 } 1. & $10-14$ & 5 & 11 \\
2. & $5-9$ & 8 & 17 \\
\cline { 2 - 4 } & $0-4$ & 33 & 72 \\
\hline & Total & 46 & 100 \\
\hline
\end{tabular}

(Source: Field work, (2018)).

Table 3 revealed that the majority (77\%) of scientists of the CSIR-BRRI were visible on the web with at least one web mention. Aaltojarvi (2008), suggested that a web mention was indicative of web visibility. It is right to conclude that scientists of the CSIRBRRI were largely visible on the World Wide Web. The remaining 23\% had no web mention. This could be due to the fact that, their research might have been published in journals which did not archive articles online. As shown in Table 3 above, the study observed that out of 46 scientists, $31(77 \%)$ had at least one scholarly publication (hits) mentioned online. Only $11 \%$ had more than 10 or more hits while some $17 \%$ had between 5 to 10 hits. 


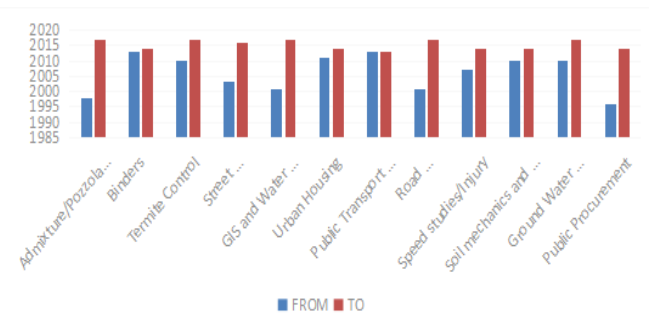

Fig. 2: Year Range for Hits observed per subject area

(Source: Field work, (2018)

The results as indicated in Fig 1 showed that all publications by scientists ranged from 1996 to 2017. The oldest mention of an active scientist of the Institute on the internet was in 1996 in an article classified under public procurement as a subject area. Also, the results showed that scientists had been vastly consistent in the subjects they published in, with perceptions of public transport in Ghana being the only subject which seemed like a one-off study that had not had follow-up studies. In scientific scholarship, scientists are expected to specialize to become experts over time. Specialization allows every person to be a professional in what one does. An organization that requires that every worker is an expert to some degree results in increased production with employees who are able to refine the task for which they are responsible (Adeyoyin et al., 2015). Thus, scientists of CSIR-BRRI may be described as highly specialized.

On the other hand, this study also observed that scientists over two decades seemed to vastly focus only on a few subject areas with reduced interest in areas such as paint, earthquake studies and wood as building related subjects. This could be as a result of changing socio-cultural trends which may influence peoples' choices with regard to design and construction of buildings and roads. For instance, reduced research in bamboo and earth buildings may be as a result of changed preference towards burnt clay bricks and concrete. In addition, the overall visibility range of scientists was also determined by identifying the oldest occurrence of a publication against the most recent publication.

Impact assessment of CSIR-BRRI scientists using citation analysis

Also, hits of each scientist were assessed to determine the subjects that scientists were making global impact in. Hits were later organized under subject areas. Table 4 shows the various areas that scientists were being cited.

TABLE 4

Citations grouped under subject areas.

\begin{tabular}{llcc}
\cline { 2 - 3 } 1. & Subject Area & Citations & Admixture/Pozzolana \\
\cline { 2 - 3 } 2. & Binders & 5 & $0.80 \%$ \\
3. & Termite Control & 14 & 0.0004 \\
4. & Street Vending/Trading & 10 & 0.95 \\
5. & GIS and Water & & \\
Quality (Chemical & 1 & 0.00009 \\
6. & Uralysis) & & \\
7. & Public Transport Studies & 15 & 0.14 \\
8. & Road Safety/Accidents & 310 & 2.96 \\
9. & Speed studies/Injury & 9804 & 93.74 \\
10. & Soil mechanics and GIS & 44 & 0.42 \\
11. & Ground Water / Water & 9 & 0.86 \\
12. & Public Procurement & 133 & 1.27 \\
\hline & Total & 10,458 & \\
\hline
\end{tabular}

(Source: Field work, (2018)

Citations refer to the use and acknowledgement of a research work. Citations have been used to measure relevance or impact of published 
works. As indicated in Table 4, the most cited subject area was speed studies and injury control with a total of 9804 citations constituting $94 \%$ of all citations found. The distribution of citations was highly skewed with accidents and road safety studies publications being highly cited (310) while GIS and Water Quality were the least (9) cited. This finding is consistent with findings by (Schmoch, 2020), that the distribution of the number of citations per research units are often skewed. Web presence was thus analysed by counting the number of webs mentions and co mentions as indicated by the number of hits made by an individual researcher (Chung \& Park, 2012). Indeed, the fact that some journals are making efforts to archive back issues of articles online must have accounted for the articles mentioned in the 1990's.

\section{TABLE 5}

Contributions of scientists based on gender as found in Google Scholar.

\begin{tabular}{|c|c|c|c|c|}
\hline $\begin{array}{l}\text { Ge n - } \\
\text { der }\end{array}$ & $\begin{array}{l}\text { No of } \\
\text { Hits }\end{array}$ & $\%$ & $\begin{array}{c}\text { No. of } \\
\text { Citations }\end{array}$ & $\%$ \\
\hline Male & 165 & 91 & 10,366 & 99 \\
\hline Female & 16 & 9 & 92 & 1 \\
\hline Total & 181 & 100 & 10,458 & 100 \\
\hline
\end{tabular}

\section{(Source: Field work, (2018)}

Table 5 shows results of contributions of scientists based on gender. As displayed in the table, female scientists had contributed $9 \%$ of all hits found with an impact rate of $1 \%$. Though very minimal, women scientists of CSIR-BRRI are visible online and making efforts to contribute to scientific research. This finding supports the views of (FitzGerald et. al. 2019; Ohemeng \& Adusah-Karikari, 2015); regarding science, research and gender; that females are often seen as constituting a minority and seem to struggle to break through although some recent studies have reported an increase in female authorship (Gay-Antaki
\& Liverman, 2018). However, the presence of women scientists who are focused and contributing to knowledge though small in number is laudable.

TABLE 6

Institutional repository related hits.

\begin{tabular}{lc}
\hline No $\quad$ Subject Area & $\begin{array}{c}\text { Institutional } \\
\text { Repository }\end{array}$ \\
\hline 1 Admixture/Pozzolana & 3 \\
2 Binders & 0 \\
4 Termite Control & 1 \\
3 Street Vending/Trading & 1 \\
4 GIS and Water Quality & 1 \\
5 Urban Housing & 2 \\
6 Public Transport Studies & 0 \\
7 Road Safety/Accidents & 1 \\
8 Speed studies/Injury & 0 \\
9 Soil mechanics and GIS & 0 \\
11 Ground Water Management & 0 \\
12 Public Procurement & 1 \\
\hline Total & $\mathbf{1 0}$ \\
\hline
\end{tabular}

(Source: Field work, (2018)

Another dimension that this study observed was visibility of scientists in Institutional Repositories. Table 5 showed a total of 10 hits out of the overall hit capacity of 181 . This observation of hits in repositories of Institutions of higher learning could be attributed to the fact that research scientists had attended school either to acquire MSc. or PhD degrees from these Universities. Again, it was observed that all scientists who were visible online always $(100 \%)$ indicated affiliation to CSIR-BRRI as a parent institution even though they had published in journals, conferences etc. This phenomenon is described as affiliated authorship. However, there was no hit which 
had a direct link to the Institute's website as experienced by institutions of higher learning such as Kwame Nkrumah University of Science and Technology (KNUST), which always had a link to the University's website or repository especially regarding thesis and other publications). Again, out of the total hits made, there were only three (3) Scientists who had a direct reference (not given as reference to a journal or conference paper) to the CSIR-BRRI as a parent institution with their Institutional/staff emails attached. There were indications of collaboration between CSIRBRRI Scientists and scientists/lecturers in other organizations particularly KNUST resulting in the archiving of several publications in the KNUST space (an Institutional Repository). This may be attributed to the CSIR-BRRI's proximity to KNUST.

The study also assessed the most productive division based on web visibility. This was attained by adding up all hits made by scientists in each division to achieve the results in Figure 1 below. The Transportation Engineering Division turned out to be the most published online (96\%) of all hits found.

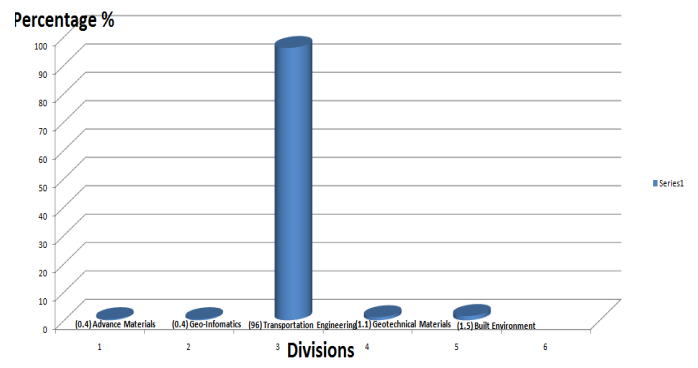

Fig. 3: Divisional web visibility

(Source: Field work, (2018)

Similarly, on the assessment of scholarly impact which was measured using the total number of citations as given on the initial Google Scholar search, scientists were largely cited in scholarly publications. On the other hand, some articles had not obtained any citations at all. This could be due to the fact that their choice of study areas was not of current interest.

Relationship between total number of journal articles and citations

The study also sought to establish whether there was a relationship between number of journal articles and citations. With a $\mathrm{p}$ value $=0.291$ which is $>$ greater than the significant level 0.05 , it was established that there was a weak positive correlation between number of articles and citations. In a correlation analysis, articles explain only $22 \%$ of the variations in citations. Thus, a higher number of journals found online for a scientist did not necessarily reflect a higher number of citations. This observation is similar to an observation by Chung \& Park (2012), that, there was a weak but statistically significant relationship between web mention and citations on Social Science Index.

Generally, it was observed that some scientists had only a few journal articles online and yet had more citations than scientists who had several journal publications visible online.

\section{Conclusion and recommendations}

The purpose of this study was to assess whether the CSIR-BRRI scientists were visible on the internet via Google Scholar. The findings indicate that scientists of the CSIR-BRRI are making diverse efforts in their various fields to promote knowledge through scholarly publishing. Also, scientists were largely visible online and generally had more hits with regard to journal publications followed by conference papers and then theses. Again, scientists' online visibility mostly came with affiliated references to the CSIR-BRRI as an 
Institute; a good projection of the image of the Institute and the CSIR as a whole. Regarding subject area citations, several publications by CSIR-BRRI scientists were making impact globally with several papers being cited by other scholars across the globe. Thus, it can be concluded that CSIR-BRRI scientists are visible online especially with regard to journal articles. This study also shows that getting a paper published particularly via the web (visibility) is only the beginning of scholarly impact; citations look beyond visibility and connote re-use by other authors in the continuity of knowledge. Citation counts seem to give a better assessment of impact as against number of publications since scientists with fewer publications rather had more citations. The primary limitation of the study was the small size of the population studied although each member of the population was considered. Despite this limitation, the study contributes significantly to research, especially because it is the first to show empirically CSIR-BRRI's visibility and impact of scientific research on the web. The study also generates several important questions for future research including a comparative assessment of scientists' electronic versus print publications, expansion of scholarly assessment and impact to include number of download statistics for PDF, Excel and word document and appearances in high impact journals.

The Institute must endeavor to have an official web presence with both previous and present publications, particularly, technical reports, edited research reports, special reports, and to show a collective effort instead of the individual and fragmented showcase of research conducted. CSIR-BRRI must get an Institutional Repository. Scientists can also enhance their visibility through collaborations especially with academic institutions which often archive publications on repositories that are hosted online. Scientists must choose high quality publication channels. Scientists must target internationally recognized conferences and journals to increase their online visibility. The Institute must ensure that scientists are properly profiled and linked to the Institutes' website with a functional institutional email to enhance credibility on the international scene. Scientists must formulate their title, abstract and keywords with caution bearing in mind that people base their interest and their searches on these three aspects of a publication. Closely related to this are the relevance and or suitability of a publication within the period it is published. Original and interesting research usually attracts renowned publishers and thus would ensure an online presence for such an endeavour. Management must also make a conscious effort to advertise the Institute's research publications and not leave the entire marketing and dissemination to individual scientists. This could be done via social media channels such as Facebook, Twitter and Linkedin. Again, the Institute's website must be updated continuously. Ultimately, an Institutional Repository would be an ideal and constant showcase of publications online.

\section{References}

Aвoushak, A. (2015) Importing Multiple Citations from Google Scholar to Endnote Library through Zotero Technical Report. December 2015. Doi:10.13140/RG.2.1.3463.4322.

ABRAMO G. (2018) Revisiting the Scientometric conceptualization of impact and its measurement. Journal of Informetrics 12, 590 - 597. https://doi.org/10.1016/j.joi.2018.05.001.

Adeyoyin, S. O., Agbeze-Unazi, F., Oyewunmi, O. O., Adegun, A. I. \& Ayodele, R. O., (2015) Effects of Job Specialization and Departmentalization on Job Satisfaction among the Staff 
of a Nigerian University Library (2015). Library Philosophy and Practice (e-Journal) 1295. http://digitalcommons.unl.edu/libphilprac/1295.

Agarwal, A., Durairajanayagam, D., Tatagari, S., Esteves, C. S., Harley, A., Henkel, R., Roychoudhury, S., Homa, S, K. O, E. Abu-Elmagd, M., Gosalvez, J. \& Bashiri, A. (2016) Bibliometrics: tracking research impact by selecting the appropriate metrics. Asian Journal of Andrology 18 (2), 296 - 309. Doi:10.4103/1008-682x.171582.

Aguinis, H., Suarez-Gonzalez, Lannelongue, I. \& Joo H. (2012) Scholarly impact Revisited. Academy of Management Perspectives 2.

Ale Ebrahim, N., Salehi, H., Embi, M. A., Tanha, F. H., Gholizadeh, H. \& Motaharhttps, S. M., (2014), Visibility and Citation Impact. International Education Studies; 7 (4). Canadian Center of Science and Education. https://www. semanticscholar.org/paper/.

Altojarvi, I., Armenin, I., Aurenen, O. \& Pasanen, H. (2008) Scientific Productivity, Web Visibility and Citation Patterns in Sixteen Nordic SociologyDepartments. Acta Sociologica 51 (1). https://journals.sagepub.com/doi/ abs/10.1177/0001699307086815.

BARNES, C. (2015) The use of altmetrics as a tool for measuring research impact. Australian Research Libraries 46 (2), 1 - 14 DOI: 1080/00048623.2014.1003174

CARLSON, J. (2014) The use of Life Cycle models in developing and supportingdata services. In Research data management: Practical strategies for Information Professionals ed.by Ray J.M..https://books.google.com.gh/books.

Carnes, M., Devine P. G., Baier M. L., Byars-WinSton, A., Fine E., Ford, C. E.,Forscher, P., Isaac, C., KaAtz, A., Magu, A. W., Palta, M. \& Sheridan, J. (2015) The effect of an intervention to break the gender bias habit for faculty at one institution: a cluster randomised, controlled trial. Acad Med. 90 (2), 221 - 30. https:/www.ncbi.nlm.nih.gov/pmc/articles/ PMC4310758/.

Charlesworth, T. E. S. \& Banaji, M. R. (2019) Gender in Science, Technology, Engineering, and Mathematics: Issues, Causes, Solutions. Journal of Neuroscience 39 (37), 7228 - 7243. https://www.ncbi.nlm.nih.gov/pmc/articles/.

Chung, C. J. \& Park, H. W. (2012) Web visibility of scholars in media and communication journals. Scientometrics 93 (1), 207 - 215.https:// doi.org/10.1007/s11192-012-0707-8.

Costas, R., Zahedi, Z. \& Wouters, P. (2015) Do Altmetrics correlate with Citations?Extensive comparisons with Altmetric Indicators with Citations fromMultidisciplinary Perspective. JASSIST 66 (10).https://asistdl.onlinelibrary. wiley.com/doi/full/10.1002/asi.23309.

Cox, A. M. \& TAm, W. W. T. (2018) A Critical Analysis of Lifecycle Models of research process and research data Management. Aslib Journal ofInformation Management 70 (2).https://doi. org/10.1108/AJIM-11-2017-0251.

Ding, Y. Zhang, G., Chambers, T., Song, M., Wang, X. \& ZHAI, C. (2014) Content based citation analysis: the next generation of citation analysis 65 (9).

Dorsch, I. (2017) Relative Visibility of authors' publications in different information Services. Scientometrics 112, 917 - $925 . \quad \mathrm{https}$ ://doi. org/10.1007/s11192-017-017-2416-9.

Fitzgerald, C., Martin, A. \& Berner, D. (2019) Interventions designed to reduce implicit prejudices and implicit stereotypes in real world contexts: a systematic review. BMC Psychol 7 (29). https://doi.org/10.1186/s40359-0190299-7.

Halevi, G., Moed, H. \& Bar-Lian, J. (2017) Suitability of Google Scholar as a source of Scientific Information and as a source of data for scientific evaluation-Review of the Literature. 
Journal of Informetrics 11 (3), 823 - 834. https://www.sciendirect.com/science/article/ abs/.

Haustein, S., Peters, I., Sugimoto, C. R., Thelwall, M. \& LARIVIÈRE, V. (2014) Tweeting biomedicine: An analysis of tweets and citations in the biomedical literature. JASIST 65 (4). https://doi.org/10.1002/asi.23101

HermanN, E. (2018) Scholarly reputation. FEMS Microbiology Letters, 365, 2018,, fny200. doi:10.1093/femsle/fny200.

Higgins, s. (2008) The DCC Curation Lifecycle Model, International Journal of Digital Curation 3 (1). https://doi.org/10.2218/ijdc.v3i1.48.

Klain-Gabbay L. \& Shoham, S. (2018) Scholarly Communication and the Academic Library: Perceptions and Recent Developments. Open Access Peer Reviewed Chapter. https://www.intechopen.com/ books/a-complex-systems-perspective.

Kurtz, M. J. \& Bollen, J. (2010) Usage Bibliometrics. Annual Review of Information Science and Technology 44 (1), 1 - 64.https://asistdl. onlinelibrary.wiley.com/doi/abs/10.1002/aris.

Lariviere, V., Ni, C., Gingrass, Y. Cronin, B. \& Sugimoto, C. R. (2013) Bibliometrics: Global gender disparities in science. Nature International Weekly Journal of Science 504 (7479), 211 - 213. https://www.google.com/.

Lee, M. S. \& PARK, H. (2012) Exploring the web visibility of world-class universities. Scientometrics 90 (1), 201 - 218.https://doi.org/10.1007/ s11192-011-0515-6.

LiM, Y. S. \& PARK, H. W. (2011) How do congressional members appear on the web? Tracking the web visibility of South Korean Politicians. Government Information Quarterly $\mathbf{2 8}$ (4), 514-521.https://www.sciencedirect.com/ science/article.
Lopez-Cozar, E. D., Robinson-Garcia, N. \& TorRes-Salinas, D.(2014) The Google Scholar Experiment: How to index false papers and manipulate bibliometric indicators. JASIST $\mathbf{6 5}$ (3).https://doi.org/10.1002/asi.23056.

Mensah, K. J. \& Bekoe, S. (2010) Journal Publishing in Ghana: Review of the state and Patronage. Journal of Building and Road Research, Ghana 12 (1).

Michener, G. \& Bersch K. (2013) Identifying Transparency. Information Polity 18, 233 - 242. DO1 10.3233/IP-130299.

Ohemeng, F. L. K. \& Adusah-Karikari, A. (2015) Breaking Through the Glass Ceiling: Strategies to Enhance the Advancement of Women in Ghana's Public Service. Journal of Asian and African Studies 50 (3), 359 - 379. https://journals.sagepub.com. DOI: 10.1177/0021909614530381.

Orduña-Malea, E. \& Delgado, L-C. E. (2015) The dark side of open access in Google and Google Scholar: the case of Latin-American repositories. Scientometrics 102, $829-846$. https://doi.org/10.1007/s11192-014-1369-5

Parra, C. Casati, F., Florian, D., Marchefse, M., Cernuzzi, L., Dumas, M., Kungas, P., García-Bañuelos, L. \& Kisselite K. (2011) Investigating the Nature of Scientific Reputation, International Society for Scientometrics and Informetrics, Durban, South Africa, July $4-7,2011$.

Rice, D. B., Raffoul, H., Loannidas, J. P. A. \& Moher, D. (2020) Academic criteria for promotion and tenure in biomedical sciences faculties: across sectional analysis of international sample of Universities. BMJ 2020; 369: m2081. https://doi.org/10.1136/bmj.m2081.

Schmoch, U. (2020) Mean Values of Skewed Distributions in the Bibliometric Assessment of Research Units. Scientometrics.https://link. springer.com/article/10.1007/s11192-02003476-8. 
Shultz, M. (2007) Comparing test searches in $\mathrm{Pu}-$ bMed and Google Scholar.Journal of Medical Library Association 95 (4), 442 - 445.http:// www.ncbi.nlm.nih.gov/pmc/articles/.

Sugimoto, C. R. (2013) Global gender disparities in science. Nature 504, 211 - 213.https://cdn. auckland.ac.nz/assets/auckland/science/current-students/docs/gender-disparities-in-science.pdf.

Thelwall, M., Haustein S, Larivière, V. \& SugimoTO, C. R. (2013) DoAltmetrics Work? Twitter and Ten Other Social Web Services. PLoS ONE 8 (5), e64841. https://doi.org/10.1371/ journal.pone. 0064841
Tomaskovic-Devey, D., Zimmer, C., Stainback, K., Robbinson, C. Taylor,T.\& Mctague, T. (2006) Documenting desegregation: Segregation in American workplaces by race, ethnicity and sex, 1966 - 2003. American sociological

UNESCO (2018) Women in Science. The gender gap in science Fact Sheet No. 51 June 2018. $\mathrm{FS} / 2018 / \mathrm{SCI} / 51$.

Wood, A., O'brien, D. R., Altman M., Karr, A. F., Gasser U., Bar-Sinai, M., Nissim, K., UllMAN, J., VADHAN, S. \& WoJciK, M. J. (2014) Integrating Approaches to Privacy across the Research Lifecycle: Long-term Longitudinal Studies. Working Paper 26p. https://pdfs.semanticscholar.org/4c93/.

Received 24 July 20; revised 21 Sep 20. 